\title{
Non-destructive Testing of Metal-Polymer Laminates with a Digital Holographic Vibrometer
}

\author{
Jagoda Nowak-Grzebyta ${ }^{1,2}\left(\right.$ I $\cdot$ Frans Meijer $^{1} \cdot$ Karol Bula $^{2} \cdot$ Ewa Stachowska $^{1}$
}

Received: 30 October 2019 / Accepted: 12 June 2020 / Published online: 24 June 2020

(c) The Author(s) 2020

\begin{abstract}
This paper presents the use of a digital holographic vibrometer to investigate metal-polymer laminates by non-destructive testing. A polymer strip was glued to a metal one of the same size. Connection defects could be detected by a local change of the vibration amplitude, even when hidden from view for the observer. The amplitudes of the oscillations excited in the samples were up to $40 \mathrm{~nm}$. This method proved to be non-destructive, allowing the samples to be (re)used after testing, or being studied with other test methods.
\end{abstract}

Keywords Polymers $\cdot$ Laminates $\cdot$ Digital holographic vibrometer $\cdot$ Connection defects

\section{Introduction}

Composite materials are nowadays widely used in many applications: aero-space, cars, wind turbines and others. The reliability of composite materials is based on the quality of the connection. The realization of good adhesion between metal and polymer can cause problems due to the difference of their surface energy. Most synthetic polymers used commercially have a low surface energy; by contrast metallic coatings have a high surface energy. This leads to low adhesion between the two materials. The key to achieve a strong polymer-metal adhesive connection is to choose materials depending on the type of function groups presented in the polymer and properly prepare its surface [1-4].

Most testing methods providing information about the strength of the connection between the components in composites cause irreparable damage to the samples tested. Such examinations make it impossible to use those samples for further analysis or (re)utilization and are called destructive testing. It is therefore desirable-or even necessary-to detect

Jagoda Nowak-Grzebyta

jagoda.pa.nowak@doctorate.put.poznan.pl

1 Division of Metrology and Measurement Systems, Institute of Mechanical Technology, Poznan University of Technology, ul. Piotrowo 3, 60-965 Poznan, Poland

2 Division of Polymer Engineering, Institute of Materials Technology, Poznan University of Technology, ul. Piotrowo 3, 60-965 Poznan, Poland hidden defects in layered structures using Non-Destructive Testing (NDT) [5-7]. During the production of polymer objects defects can occur inside the polymer, not visible from the outside when the polymer is not transparent. Another problem can arise when different parts are glued together and both parts are not sticking together in all places. A typical example is a polymer strip reinforced by a metal plate, with a local failure of the glue. It is important to check components before, during or after use for defects in such a way that they can be used or reused. A well-established method to study defects in laminates are shearographic and ultrasonic measurements [8-12]. Also Laser scanning Doppler Vibrometry [LDV] is used [9, 13-17]. We studied this type of defects with a digital holographic vibrometer, which can also be applied in a production line. The vibration and phase patterns of metal-polymer samples were analyzed with high spatial resolution and low energy excitation. Digital holographic vibrometry allows to measure amplitude and phase of many points synchronously, in our case more than 250000 , much more than with LDV, which uses typical less than 100 points $[9,16]$.

\section{Experimental}

The goal of our research is to detect unknown and invisible defects in polymer-metal laminates. The fact that the defect is unknown makes simulation very difficult and also the clamping of object and piezo transducer has to be taken into 
account. Simulating nm vibrations on objects with dimensions of $\mathrm{cm}$ is, if possible at all, also very difficult, even when the defect is known. We choose therefore to investigate such laminate defects experimentally, using the technique of holographic vibrometry. An advantage of holography is that we can observe the whole surface of a sample simultaneously and synchronously at a large number of surface points. This applies even when observing the upper and the lower sides of a sample and allows e.g. to discriminate between flexural and extensional vibration modes.

\subsection{Holographic Vibrometer}

An Optonor Vibromap 1000 digital holographic vibrometer [13] was used to test the samples. This instrument uses a frequency-doubled $150 \mathrm{~mW} \mathrm{Nd:YAG} \mathrm{laser} \mathrm{with} \mathrm{a} \mathrm{wavelength}$ of $532 \mathrm{~nm}$ as light source.

The instrument is basically a Michelson $[18,19]$ interferometer set-up. A light beam emitted from this instrument illuminates the object under study. This object is imaged onto a CCD-camera with $640 \times 480$ pixels. A second beam of the laser is internally send to the camera. The two light beams interfere on the camera and produce a hologram. The use of holography [20-23] implies that a large number of points (up to $640 \times 480$ in the case of the Vibromap 1000) can be observed simultaneously and synchronously. The object can be vibrationally excited with a sinusoidally signal transferred by a piezo transducer, PI P-010.00P with a high resonant frequency $(129 \mathrm{kHz})$ [24]. The frequency used by the Vibromap 1000 can be varied from $100 \mathrm{~Hz}$ to $25 \mathrm{MHz}$. The camera is recording at $60 \mathrm{~Hz}$ and can therefore only record a time-averaged hologram, averaged over many periods. In such a situation the intensity is a function of the amplitude, described by the Bessel function of the first kind $\mathrm{J}_{0}[22,23]$.

The excitation conditions (frequency and amplitude) of the sample are provided by a function generator under control of the program "Vibromap" by Optonor. This program also controls the recording of the hologram and is running on a dedicated PC. This control program also allows different recording modes. One of this is "real time", which was used to select appropriate frequencies. The "numerical mode" allows storing the average of several holograms in a Matlab.mat file, containing the amplitude and the phase of the hologram in matrices $A_{x, y}$, resp. $\varphi_{x, y}$ for further evaluation. The deflection in each point $\mathrm{x}, \mathrm{y}$ is given by $\Delta_{x y}=A_{x y} \cos \left(\omega t+\varphi_{x y}\right)$. The amplitude resolution of the vibrometer is better than one $\mathrm{nm}$. Objects from a few $\mathrm{cm}^{2}$ to one $\mathrm{m}^{2}$ can be studied with this instrument. A scheme of the measurement set-up is given in Fig. 1. In the standard holographic vibrometric set-up (see Fig. 1a) only one side of the sample can be seen during a measurement. For the purpose
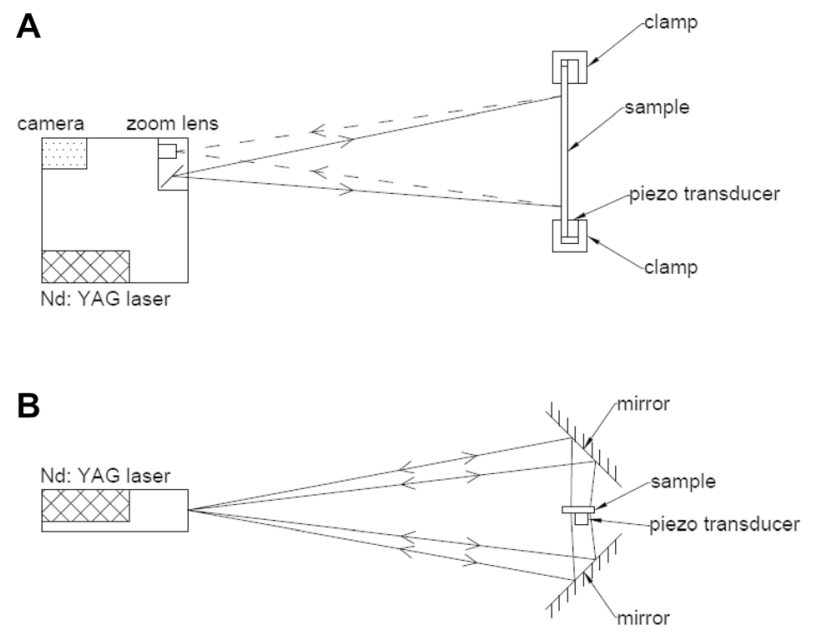

Fig. 1 Holographic vibrometric measurement set-up: a top view of a set-up to investigate one side of a sample; $\mathbf{b}$ side view of the improved set-up to look at two sides of a sample simultaneously

of this study the set-up was improved to enable observing both sides of a sample simultaneously (see Fig. 1b).

\subsection{Sample Preparation}

In our experiments polyamide 6 , injection molding grade, Tarnamid T-27 (supplied by Grupa Azoty, Tarnów, Poland), characterized by a melt volume flow index (MVI) of $120 \mathrm{~cm}^{3} / 10 \mathrm{~min}$ at $275^{\circ} \mathrm{C}$, was used. The metal plates were made of non-alloy quality steel 1.0338 (grade DC 04) En 10,130 plates, $1 \mathrm{~mm}$ thick.

The polymer strips were produced using an ENGEL 20/80 HLS injection moulding machine with a screw diameter of $22 \mathrm{~mm}$. The temperature profile along the injection barrel was $225-230-240-260{ }^{\circ} \mathrm{C}$ and the machine injection pressure was $7 \mathrm{MPa}$. The injection speed was $90 \mathrm{~mm} / \mathrm{s}$.

The steel sheets, with dimensions of $150 \times 10 \mathrm{~mm}$ (length $\times$ width), were first cleaned with ethylene alcohol to remove surface contaminations. The metal and polymer strips were than glued together at ambient temperature with epoxy Araldite 2011.

At the location of the defect the metal and polymer strips can to some extent, dependent on the frequency, vibrate independently; when glued together they influence each other. This results in different vibration patterns at defect locations.

Three different defects were created in the middle of the samples (see Fig. 2):

- an $18 \mathrm{~mm}$ long connection defect across the full width in the middle of the samples

- one with a $12 \mathrm{~mm}$ wide defect and

- one with a $6 \mathrm{~mm}$ wide defect (see Fig. 2). 

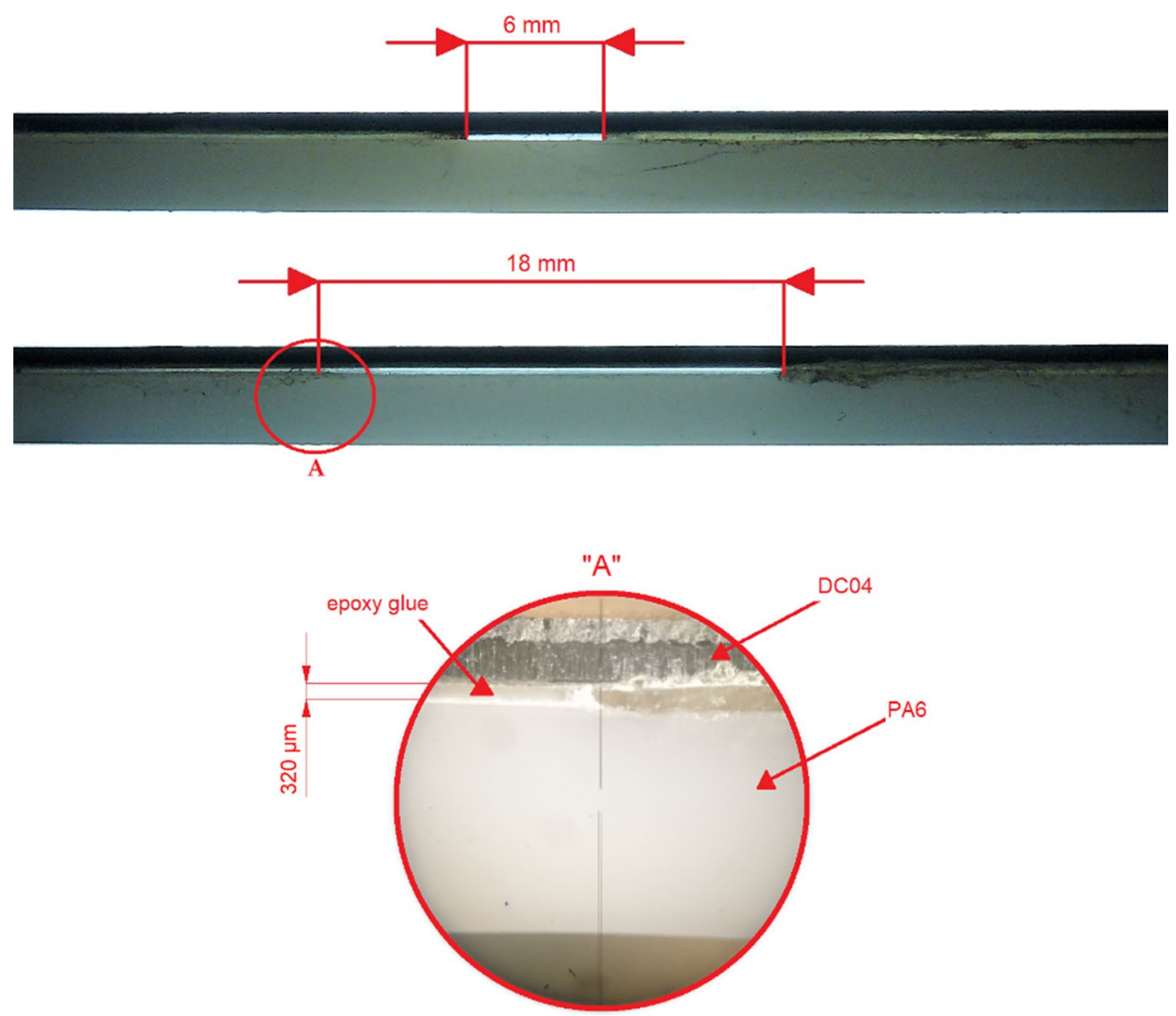

Fig. 2 Two samples with an epoxy glue layer between metal and polymer with a glue defect in the middle of the sample and a detailed picture of part of the lower one

\subsection{Sample Mounting and Excitation}

The sample holder constructed allowed observation of both sides of the sample simultaneously (see Figs. $1 \mathrm{~b}$ and $3)$. The piezo transducer could be mounted below (polymer side) or on top (metal side) of the sample (see Fig. 4).

The samples were mounted with two clamps (one on each side of the sample) (see Figs. 1, 3, 4). The excitation was induced by a piezoelectric transducer in direct contact with the surface of the sample mounted in a clamp along with the sample (see Fig. 4). The whole sample holder was mounted on a damped pillar to avoid excitation by external sources as well as avoiding exciting vibrations in the mirrors. The piezo transducer was always outside the part imaged. We registered the amplitude and phase patterns of the vibration of the sample's surfaces.

\subsection{Data Evaluation Software}

Several programs were written to extract information about the vibration patterns of the images of our samples from the time-averaged holograms. The programming language used was "R" [25], which is open source and has excellent statistical and visualization facilities and executes much faster then e.g. Octave/Matlab.

These programs were running on a GNU/Linux desktop computer, which allows a more efficient handling of the large amount of data obtained. In $\mathrm{R}$ it is easy to extract the matrices describing the amplitude resp. the phase from the. mat files mentioned in Sect. 2.1. The R-packages "EBImage" and "plot3D" were very useful in visualizing features of the vibration patterns, while "pracma" offered some useful mathematics routines. The resulting pictures varied 


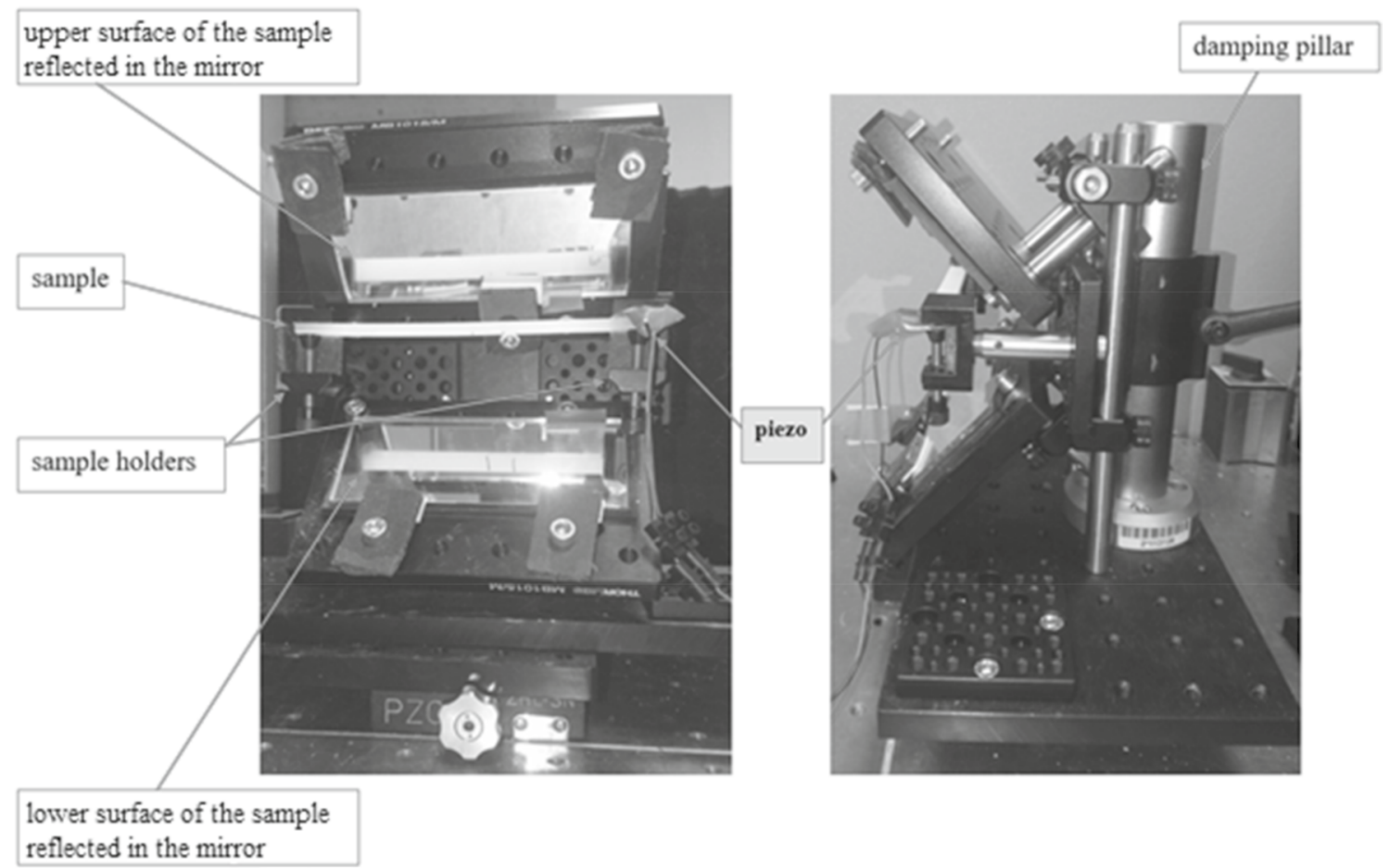

Fig. 3 Sample mounting system and mirror placement

Fig. 4 Piezo transducer and sample mounting system

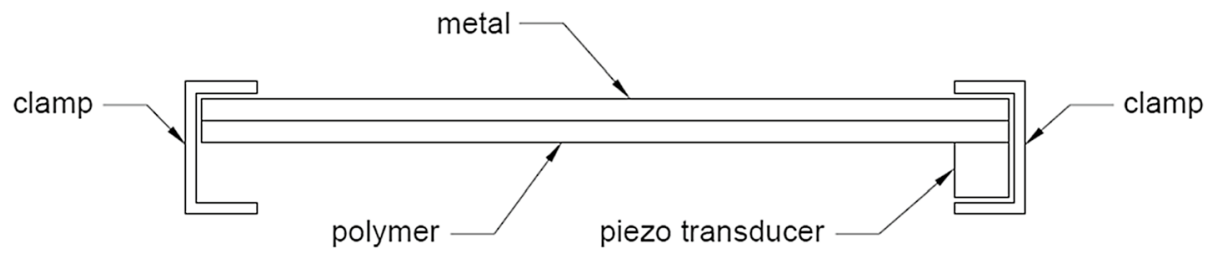

from simple two-dimensional plots of the amplitude and the phase patterns on our samples (see e.g. Fig. 5) to threedimensional animations. Stills from these animations are also very helpful to study properties of our samples (see e.g. Fig. 6). From the latter we also constructed deflection patterns, averaged over one dimension of our sample (see Fig. 7). All programs offer the possibility to view upper $\left(t_{v}\right)$ and under-side $\left(b_{v}\right)$ of the sample in one picture or animation, which is useful in comparing both sides.

\section{Results}

\subsection{Detection of a Defect}

The repeatability of the resonant frequencies and spatial distributions of vibrations with amplitudes in the range of nanometers were examined. All samples were tested in the same frequency range (200-125 $000 \mathrm{~Hz}$, limited by the available piezo-transducer) to determine resonant frequencies. The resonant frequencies and spatial distributions of vibrations were highly repeatable.

The quality of the connection between metal and polymer (see Sect. 2.2) was tested. A clear difference in the amplitude pattern was found between samples without and with a glue defect (see Figs. 5, 6, 7). Samples without a glue defect had a regular pattern similar for both sides of the sample for both amplitude and phase (see Fig. 5). Samples with a glue defect showed a large amplitude maximum in the localization of the defect (the rest of the sample had a very low amplitude) and an often less regular phase distribution (see Figs. 5, $6,7,8,9)$. 

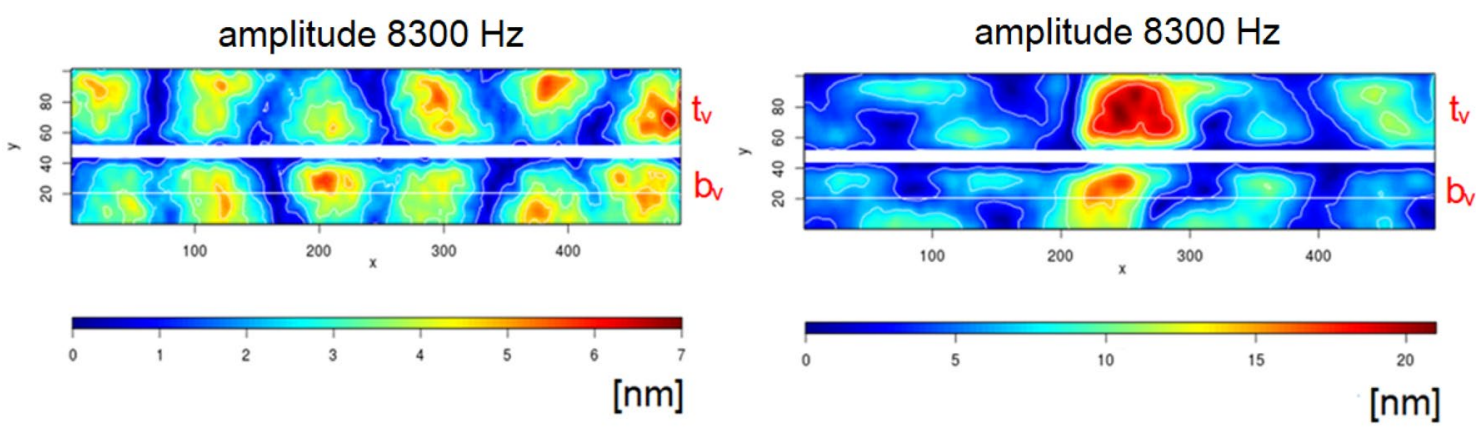

Fig. 5 Amplitude patterns for two samples: left—without a glue defect, right—with a glue defect; excitation frequency $8300 \mathrm{~Hz}$; $\mathrm{x}$ and $\mathrm{y}$ axes in units of pixels, $\mathrm{t}_{\mathrm{v}}$ : top view, $\mathrm{b}_{\mathrm{v}}$ : bottom view (see Fig. 2). The size of the visible part of the sample is $84 \times 10 \mathrm{~mm}^{2}$

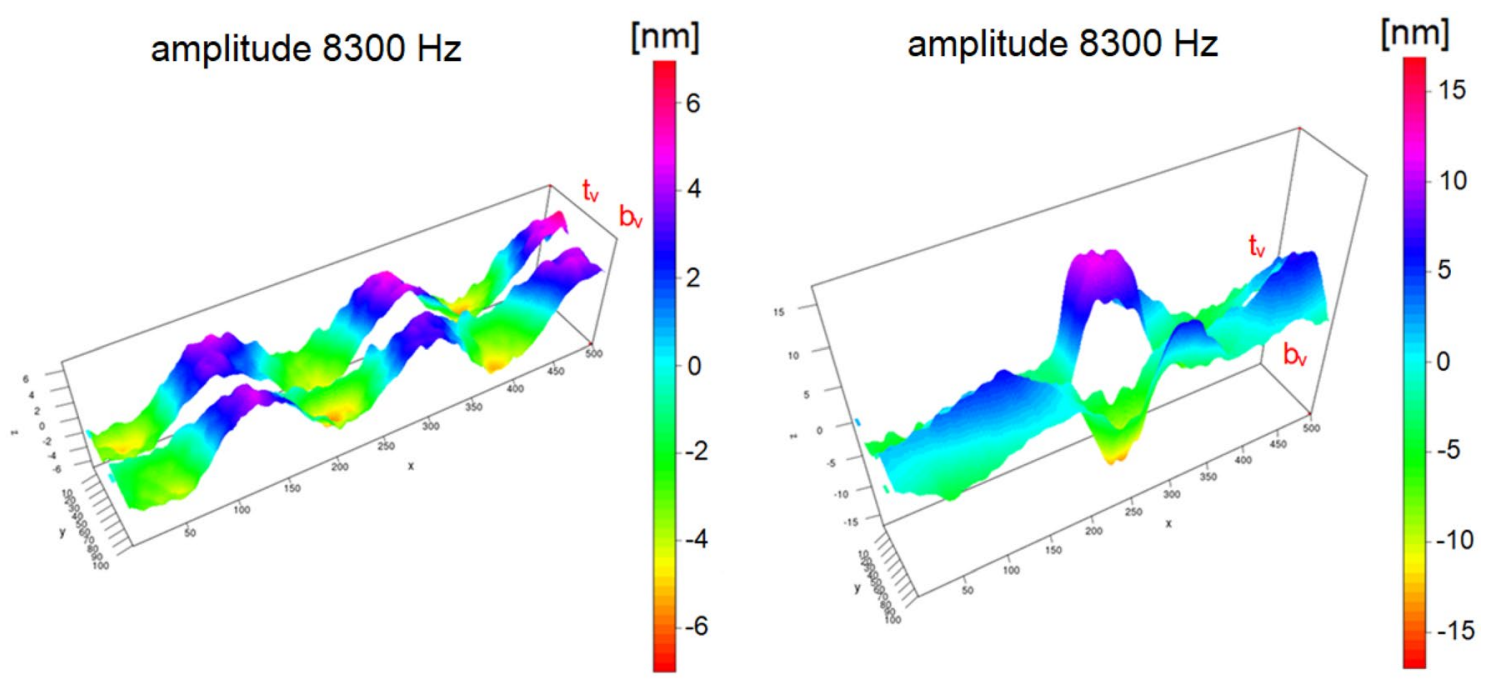

Fig. $63 \mathrm{D}$ plot of the vibration pattern at one moment in the vibration cycle; $\mathrm{t}_{\mathrm{v}}$ : rear part top view; $\mathrm{b}_{\mathrm{v}}$ : front part bottom view; left-without a glue defect, right—with a glue defect; excitation frequency $8300 \mathrm{~Hz} ; \mathrm{z}$ axis_-amplitude in nanometers, $\mathrm{x}$ and $\mathrm{y}$ axes in units of pixels

\subsection{Frequency Range of Response to a Defect}

Our method can be considered as a kind of LDR (Local Defect Resonance) [26-29] but with a wider frequency response (see Fig. 8). This makes it possible to scan the whole frequency range we use $(200-130000 \mathrm{~Hz})$ with large steps and then investigate the relevant frequency region in more detail. To model the defect is therefore not necessary and in a practical case, when location, size and shape are not known, in fact impossible.

\subsection{Three Samples with Different Defect Size}

Three samples with defects of different size were tested to see if they gave different results (see Fig. 9). Not only the different sizes could be observed but the resonant frequencies were also clearly different. In all cases no defects could be localized using subharmonic or higher harmonic excitation.

From Fig. 9 it is also clear that at the defect location the phase pattern changes too. In the leftmost picture the phase of the upper and the lower view differ by about $\pi$, except at the location of the defect. This means that when one side moves towards the observer, the other side moves away. Outside the defect both sides move therefore in the 


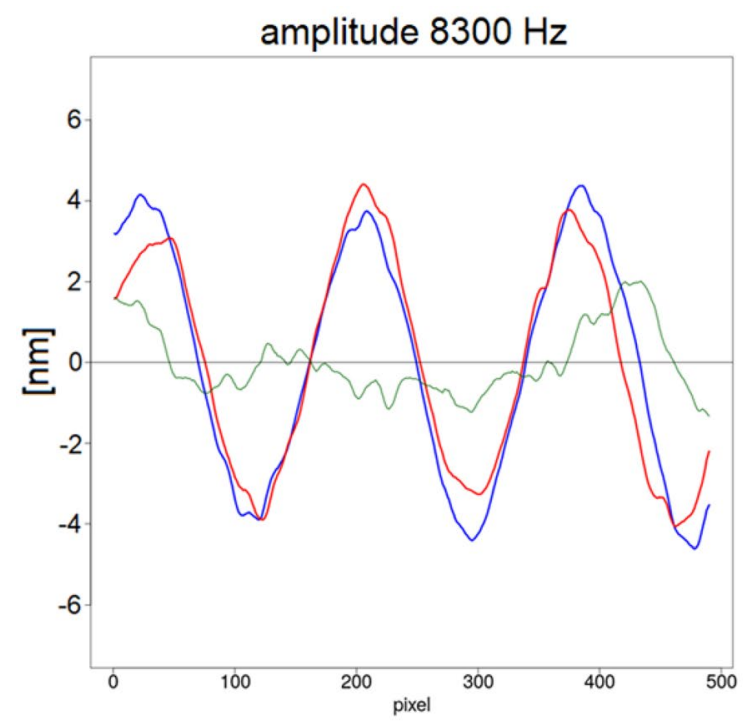

Fig. 7 Amplitude [nm], averaged over the y-direction, of two samples for an excitation frequency of $8300 \mathrm{~Hz}$ : left—without a glue defect, right—with a glue defect; blue-polymer side $\left(b_{v}\right)$; red-metal side

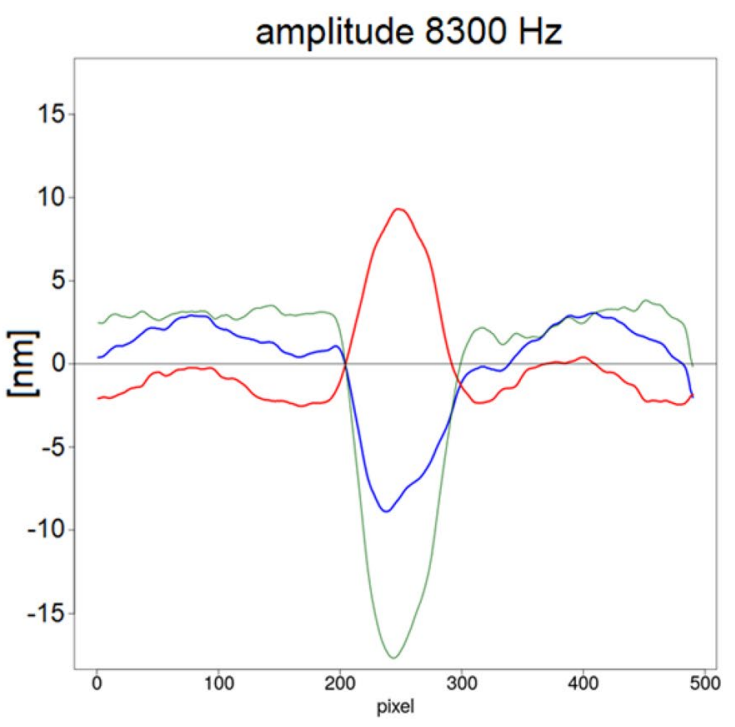

$\left(\mathrm{t}_{\mathrm{v}}\right)$; green-difference between metal and polymer amplitude (Color figure online)
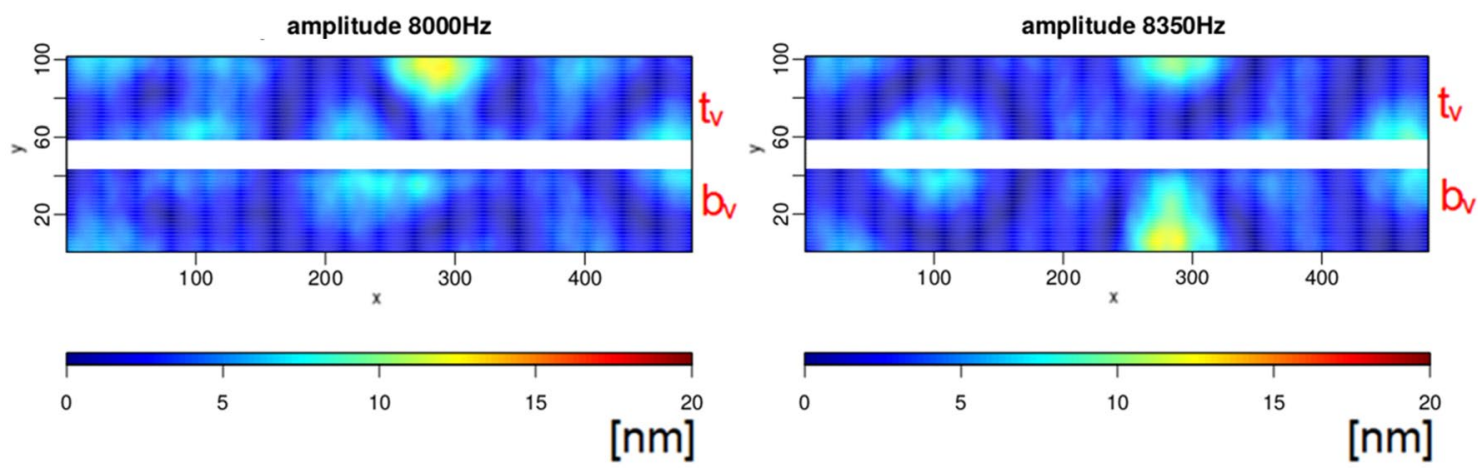

Fig. 8 The defect can be located using a wide frequency range; here $350 \mathrm{~Hz}$ for the sample with an $18 \mathrm{~mm}$ wide defect

same direction, as in Fig. 6 left and we have a flexural mode. On the location of the defect the phases are more equal, especially in the rightmost picture: they move in opposite direction as in Fig. 6 right (extensional mode). The center picture shows another advantage of using the phase pattern: on the lower (polymer) side the phase on the front edge (blue-green) is opposite to the phase on the rear edge (purple); the sample exhibits torsion: one edge moves upwards when the other moves downwards. This is confirmed by the animations produced by our evaluation software (see paragraph 2.4). The metal side is almost not affected. Using the phase makes it possible, although more difficult, to locate defects, even when the amplitude is very small.

\section{Summary}

With NDT digital holographic vibrometry we could detect defects in metal-polymer laminates with high spatial resolution and low energy excitation. The vibration amplitudes observed had a magnitude of only up to $40 \mathrm{~nm}$, which helps to avoid damage to the sample. Also the phase patterns can be very helpful. A glue layer defect between metal and polymer can be seen even when hidden from view. The resonant frequency depends strongly on the size of the defect. The programs developed allow to investigate clearly and in detail metal-polymer laminates.

Our non-destructive method makes it possible to determine location, size and shape of defects in metal-polymer laminates, allowing the objects tested to be (re)used after 

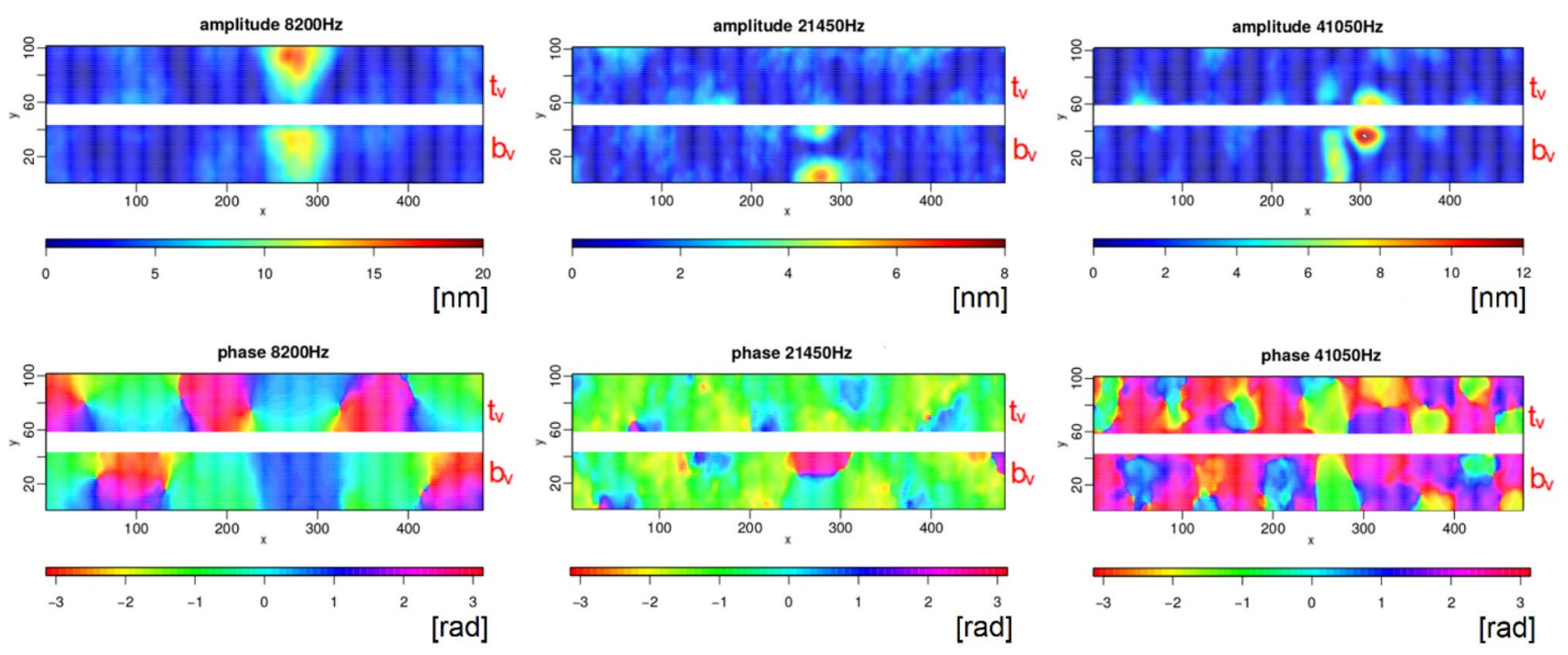

Fig. 9 Three samples with different defect sizes: from left to right $18 \mathrm{~mm}, 12 \mathrm{~mm}$ resp. $6 \mathrm{~mm}$ wide, running from rear to front edge. The sample in the rightmost picture had a second small defect to the right side of the main one, only at the rear edge

testing; important in a production line. They can also be studied with other (eventually destructive) test methods.

Acknowledgements The work was financially supported by the Polish National Centre of Science; contract Grant Number: OPUS2016/21/B/ST8/03152. ES acknowledges partial support by Project 02/220SBAD/1501 of the Poznan University of Technology.

Open Access This article is licensed under a Creative Commons Attribution 4.0 International License, which permits use, sharing, adaptation, distribution and reproduction in any medium or format, as long as you give appropriate credit to the original author(s) and the source, provide a link to the Creative Commons licence, and indicate if changes were made. The images or other third party material in this article are included in the article's Creative Commons licence, unless indicated otherwise in a credit line to the material. If material is not included in the article's Creative Commons licence and your intended use is not permitted by statutory regulation or exceeds the permitted use, you will need to obtain permission directly from the copyright holder. To view a copy of this licence, visit http://creativecommons.org/licenses/by/4.0/.

\section{References}

1. Venables, J.D.: Adhesion and durability of metal/polymer bonds. In: Mittal, K.L. (ed.) Adhesive Joints. Springer, Boston (1984). https://doi.org/10.1007/978-1-4613-2749-3_27

2. Skeist, I.: Handbook of Adhesives. Van Nostrand Reinhold, New York (1990)

3. Charlier, J.: Nondestructive testing applied to the measurement of the adhesion between metal, ceramics and high polymers. In: Van Hemelrijck, D., Anastassopoulos, A. (eds.) Non Destructive Testing, pp. 49-56. Balkema, Rotterdam (1996)

4. Kisin, S.: Adhesion Changes at Metal-Polymer Interfaces: Study of the Copper-(Acrylonitrile-Butadiene-Styrene) System.
Technische Universiteit Eindhoven, Eindhoven (2007). https://doi. org/10.6100/IR617210

5. Arkin, W.T.: New Developments in Lasers and Electro-optics Research, pp. 194-214. Nova Science Publishers, New York (2007)

6. Aryan, P., Kotousov, A., Ng, C.T., Cazzolato, B.S.: A baselinefree and non-contact method for detection and imaging of structural damage using 3D laser vibrometry. Struct. Control Health Monit. (2016). https://doi.org/10.1002/stc.1894

7. Hung, Y.Y.: Shearography: a new optical method for strain measurement and nondestructive testing. Opt. Eng. (1982). https ://doi.org/10.1117/12.7972920

8. Francis, D., Tatam, R.P., Groves, R.M.: Shearography technology and applications: a review. Meas. Sci. Technol. (2010). https://doi.org/10.1088/0957-0233/21/10/102001

9. Martarelli, M., Chiariotti, P., Pezzola, M., Castellini, P.: Delamination detection in composites by laser ultrasonics. AIP Conf. Proc. (2014). https://doi.org/10.1063/1.4879609

10. Derusova, D.A., Vavilov, V.P., Sfarra, S., Sarasini, F., Druzhinin, N.V.: Applying ultrasonic resonance vibrometry for the evaluation of impact damage in natural/synthetic fibre reinforced composites. Polym. Test. (2018). https://doi. org/10.1016/j.polymertesting.2018.03.053

11. Salmi, A., Heino, O., Nieminen, H.J., et al.: Detecting defects in adhesion between a metal hemisphere and a polymer base. In: 2013 IEEE International Ultrasonics Symposium (IUS), pp 169201695 (2013). https://doi.org/10.1109/ULTSY M.2013.0179

12. Zhang, B., Zheng, X., Xu, W., Yang, L.: Overview of digital shearography for NDT. Mater. Eval. (2020). https://doi. org/10.32548/2020.me-04120

13. Optonor, A.S.: Trondheim, Norway. https://optonor.com/. Accessed 4 July 2019

14. Kosmatka, J., Foerster, Ch, Valdes, A.: An improved ground vibration testing approach of flight vehicle structures using a scanning laser vibrometer. Struct. Dyn. Mater. Conf. (2012). https://doi.org/10.2514/6.2012-1884

15. Khan, A.A., Dai, Z., Cortina, M.S., Chamon, W., Royston, T.J.: Localized elastography map of human cornea through surface 
vibrations. ASME 2013 Int. Mech. Eng. Congr. Expos. (2014). https://doi.org/10.1115/IMECE2013-64016

16. Nutakor, C., Semken, R.S., Heikkinen, J.E., Sopanen, J., Mikkola, A.: Layered sheet-steel damping estimation using optical vibrometry. In: ASME 2015 International Design Engineering Technical Conferences and Computers and Information in Engineering Conference (2016). https://doi.org/10.1115/DETC2015-46867

17. Krasnoveikin, V.A., Konovalenko, I.S.: Development of the noncontact approach to testing the dynamic characteristics of carbon fiber reinforced polymer composites. In: 12th International Conference on Mechanics, Resource and Diagnostics of Materials and Structures (2018). https://doi.org/10.1063/1.5084486

18. Michelson, A.A.: The relative motion oft he earth and the luminiferous ether. J. Sci Am (1881). https://doi.org/10.2475/ajs. s3-22.128.120

19. Born, M., Wolf, E.: Principles of Optics, 4th edn. Pergamon Press, Oxford (1970)

20. Gabor, D.: A new microscopic principle. Nature (1948). https:// doi.org/10.1038/161777a0

21. Françon, M.: Holographie. Masson and Cie, Paris (1969)

22. Caulfield, H.: Handbook of Optical Holography. Academic Press, New York (1979)

23. Picart, P., Li, J.: Digital Holography, Ch. 7. ISTE Ltd, London (2012). https://doi.org/10.1002/9781118562567

24. P010.00P PICA Power Piezo Actuator, Physik Instrumente, Germany. https://www.physikinstrumente.com/en/products/piezoelect ric-transducers-actuators/p-010xxp-p-056xxp-pica-power-piezo -actuators-102700/\#specification. Accessed 1 June 2020

25. The R Project for Statistical Computing. https://www.r-proje ct.org/about.html. Accessed 4 July 2019

26. Solodov, I., Rahammer, M., Gulnizkij, N., Kreutzbruck, M.: Noncontact sonic NDE defect imaging via local defect resonance. J. Nondestruct. Eval. (2016). https://doi.org/10.1007/s1092 1-016-0364-6

27. Adebahr, W., Solodov, I., Rahammer, M., Gulnizkij, N., Kreutzbruck, M.: Local defect resonance for sensitive non-destructive testing. AIP Conf. Proc. (2016). https://doi.org/10.1063/1.49405 04

28. Solodov, I., Bai, J., Bekgulyan, S., Busse, G.: A local defect resonance to enhance acoustic ware-defect interaction in ultrasonic nondestructive evaluation. Appl. Phys. Lett. (2011). https://doi. org/10.1063/1.3663872

29. Segers, J., Kersemans, M., Verboven, E., Hedayatrasa, S., Calderon, J., Van Paepegem, W.: Investigation to local defect resonance for non-destructive testing of composites. Proceedings 2018 (2018). https://doi.org/10.3390/ICEM18-05273

Publisher's Note Springer Nature remains neutral with regard to jurisdictional claims in published maps and institutional affiliations. 